Olena Hrabovska,

Doctor of Technical Sciences, Professor Kyiv National University of Trade and Economics,

Kyiv, Ukraine

ORCID: 0000-0001-6462-3790

ResearcherID: https://knute.edu. ua/file/NzU4Nw==/79be468b4b2784d1d4dd7ab19f4a7b16. pdf

Hanna Pastuch,

Candidate of Technical Sciences National University of Food Technology

Kyiv, Ukraine

ORCID: 0000-0003-3846-7418

Alina Nakonechna,

Candidate of Technical Sciences, National University of Food Technology

Kyiv, Ukraine

ORCID: 0000-0003-3494-9540

\title{
POTATO FIBER AS A FUNCTIONAL SUPPLEMENT FOR USE IN RESTAURANT TECHNOLOGIES
}

Methods of producing potato powder for use as a functional biologically active additive in food are discussed. The physicochemical properties of potato powders obtained in various ways have been investigated.

Keywords: dietary fiber, functional additive, potato pulp, physico-chemical properties.

Relevance of the research topic. Due to the difficult ecological situation in Ukraine, there are insufficient products and biologically active additives of radioprotective, immunostimulating and general strengthening action in the diet. For today, the fastest, most cost-effective and technologically accessible way of improving population nutrition is the production of functional food products based on the enrichment of traditional food products with biologically active components of vegetable raw materials. That is why, research into the possibility of processing secondary vegetable raw materials into valuable functional additives and enrichment of food products with biologically active substances is relevant.

Formulation of the problem. Recently, health nutritionists have been paying attention to the importance of consuming dietary fiber. Dietary fiber mechanically 
stimulates the gut, which is so important in our time of sedentary lifestyle; promote the adsorption of toxic substances; regulate physiological, biochemical processes in the digestive system. The main source of dietary fiber is vegetable raw materials. Potato pulp, which is a secondary raw material of starch production, can be a valuable source of dietary fiber, since the content of dietary fiber in it can reach $70 \mathrm{~g} / 100 \mathrm{~g}[5,6,8]$. Potato fiber contains less phytic acid than the cereal fiber most commonly used in food, which negatively affects the absorption of minerals. Potato powders contain a large amount of folate and belong to the folate-containing group, and consumption of food products enriched with folate-containing powders is extremely important for pregnant women and the elderly [9]. Many imported food supplements (BAAs) made from potato raw materials are presented on the market, which have a high price and are therefore not available for use in the industrial production of food products and restaurant technologies.

Annually the mass of starch production waste - potato pulp - only in Europe is over 1 million tonnes, including about 40,000 tonnes in Ukraine. The high pectin content (up to $10 \%$ by weight of solids) makes it an attractive raw material for the production of functional nutritional supplements [3]. Today, however, in Ukraine potato pulp are partially fed to livestock, and more are used to fertilize fields. The research how to get potato pulp powders and study their properties solves two problems. The first is the utilization of a large amount of pulp and the improvement of the environmental situation around enterprises of starches product, and the second is the supply to the market of a valuable dietary supplement enriched with dietary fiber.

Analysis of recent research and publications. It is known from the literature that potato pulp can be used in food: fruit compotes, jams, tomato paste, fruit juices, bakery products $[1,2,8]$. Due to the content of the stromatic polysaccharides, the pulp has a high hydration capacity, it does not change either the aroma, the taste, or the $\mathrm{pH}$ of the products to which it is added, and is also quite stable under the conditions of food processing (temperature, $\mathrm{pH}$ ). Potato pulp after pectin removal has a softened structure and can be a raw material for the production of food powders [3, 7].

Potato pulp can also act as a source of dietary fiber. It should be noted that the role in the body of dietary fiber is to regulate intestinal peristalsis, promotes a sense of satiety during ingestion, creating the necessary conditions for the functioning of the normal intestinal microflora, stimulate the excretion of cholesterol from bile, reduction and delay of glucose uptake time, which is significant enough for patients with diabetes, support of water-salt metabolism, elimination from the body of heavy metals, due to its good sorption properties, prevention of colon cancer. Optimal intake of dietary fiber per day is $40 \ldots 70 \mathrm{~g}$ [1].

Potato pulp is a complex system consisting of four types of polysaccharides: cellulose, hemicellulose, pectin, starch. The ratio of these polysaccharides depends to a large extent on the potato variety, growing conditions and technology of starch extraction [3]. Such a chemical composition makes it an attractive raw material for the 
production of pectin and pectin-containing powders. The study of the physicochemical properties of potato pulp and the development of methods for producing food powders rich in dietary fiber are relevant.

The ways to obtain and study the main technological characteristics of powders obtained in different ways from potato pulp were the purpose of investigation.

Presenting main material. For research, used potato pulp, pre-washed from starch with humidity $72 \%$.

The potato powders were obtained in two ways: 1) the potato pulp was washed under running water to remove starch and soluble ballast compounds, dried and ground to a powdered state; 2) the potato pulp was washed under running water to remove starch and soluble ballast compounds, subjected to acid-thermal hydrolysis, removed the liquid phase, washed with water, dried and crushed.

The physicochemical properties of the obtained powders were investigated, namely the ability to swell, the binding of moisture and rheological characteristics [4].

Table 1

\section{Physico-chemical properties of potato powders}

\begin{tabular}{|l|c|c|}
\hline \multicolumn{1}{|c|}{ Indicators } & $\begin{array}{c}\text { Powder from non-hydrolyzed } \\
\text { pulp } \\
\text { Sample № 1 }\end{array}$ & $\begin{array}{c}\text { Powder from hydrolyzed pulp } \\
\text { Sample № 2 }\end{array}$ \\
\hline Humidity, \% & 8,45 & 8,47 \\
\hline Total ash content, \% & 1,31 & 1,20 \\
\hline Hydrophilicity, \% & 40,0 & 75,20 \\
\hline $\begin{array}{l}\text { The ability to bind water } \\
\text { at temperatures of } 20^{\circ} \mathrm{C}\end{array}$ & 5,50 & 4,70 \\
at $60^{\circ} \mathrm{C}$ & 7,26 & 6,23 \\
\hline Viscosity of the non-destructive & & \\
structure, $\eta_{0}, \mathrm{~Pa} \cdot \mathrm{s}$ & 1,86 & 3,72 \\
5\% solution & 474,47 & 47,28 \\
$10 \%$ solution & & \\
\hline Viscosity of the destructive & & \\
structure, $\eta 0, \mathrm{~Pa} \cdot \mathrm{s}$ & 0,23 & 0,11 \\
5\% solution & 11,72 & 1,73 \\
$10 \%$ solution & & \\
\hline
\end{tabular}

The table shows that both samples of powders have a high hydrophilicity, and the powder from the hydrolyzed pulp has twice the performance. However, the best ability to bind water is with sample №1, with increasing temperature, which makes it possible to recommend these food powders for foods that are subject to heat treatment.

A study was conducted to determine the maximum degree of powder swelling in the form of dried plates. Better swelling ability has hydrolyzed pulp powder. This is 
due to the fact that in the process of acid-thermal hydrolysis of the potato pulp is hydrolytic cleavage of protopectin, partly cellulose, and starch, resulting in a significant increase in the amount of hydrophilic groups in the pulp.

From the obtained powders were prepared aqueous suspensions of different concentrations, heated to a temperature of $90^{\circ} \mathrm{C}$, cooled and measured rheological parameters on a rotary viscometer type «REOTEST $-2 »$. On the basis of experimental measurements, complete rheological viscosity and flow curves were constructed, from which the strength of the structural framework $\mathrm{P}_{\mathrm{m}}$ formed in the system was calculated [4].

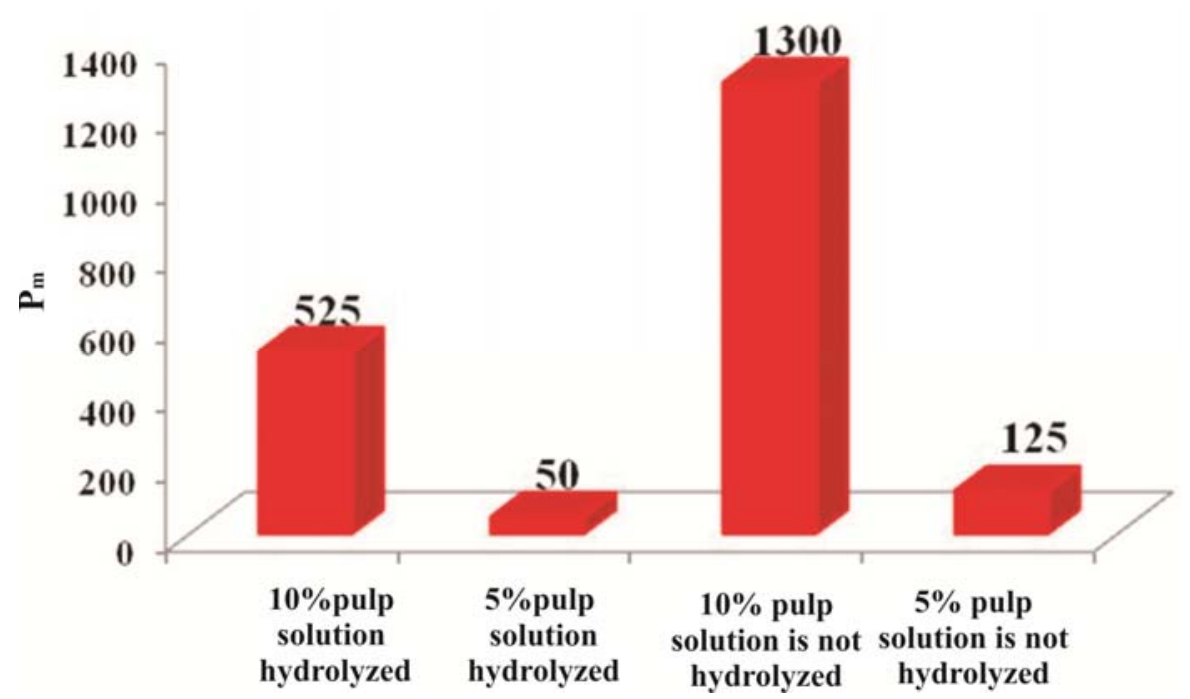

Figure 1. Strength indicator of the formed structural framework, $P_{m}$

The diagram (Fig. 1) shows that the strength index of the formed structural frame depends on the method of obtaining potato powder and the concentration of the prepared suspension. The sample of hydrolyzed pulp powder at a concentration of 5\% solution forms a suspension with virtually no structure and strength of only $50 \mathrm{~Pa}$.

A sample of a powder of non-hydrolyzed pulp of the same concentration forms a weak structure with strength of $125 \mathrm{PA}$. When the concentration of the suspension is increased to $10 \%$, sample № 2 obtained from the hydrolyzed pulp, when dissolved in water, forms a structure whose frame strength is $525 \mathrm{~Pa}$. And sample №1, at a concentration of suspension of $10 \%$ gives the strength of the structural frame 10 times greater than the same sample at a concentration of 5\%, namely - $1300 \mathrm{~Pa}$. In our view, the sharp increase in the viscosity of the slurry and the strength of the structural bonds of non-hydrolyzed starch with increasing concentration can be explained by the gelatinization of the starch that is part of the pulp when heated. Under the conditions of acid-thermal hydrolysis, hydrolytic cleavage of starch polysaccharides occurs and their separation from the pulp with the liquid phase. 


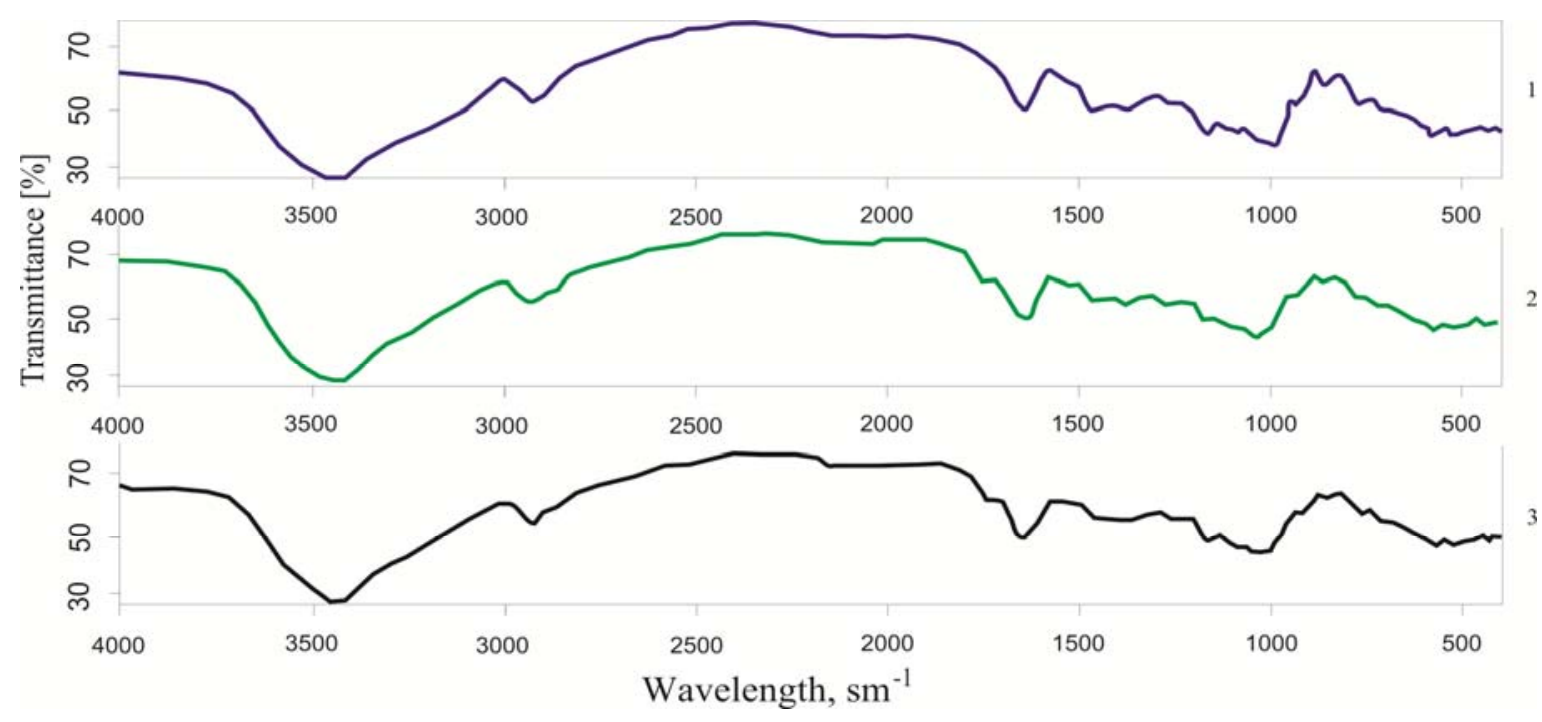

Figure 2. IR spectra: 1 - potato starch; 2 -potato powder from hydrolyzed pulp; 3 - potato pulp powder

To study the composition of potato powders we used the method of IR spectroscopy (Fig. 3). Potato pulp is mainly composed of polysaccharides, so we considered only bands whose identification is sufficiently reliable and in line with other researchers. As reference samples were taken the spectra of starch and potato pectin.

As can be seen from Figure 2, samples of food powders from potato pulp and from hydrolyzed potato pulp contain a large amount of starch. Both samples of potato powders also contain pectin, as evidenced by peaks in the region of $1740-1700 \mathrm{~cm}^{-1}$, which are also present in pectin and characterize the presence of free and methoxylated carboxyl groups. This band is absent in the spectra of potato starch and appears as a shoulder in the spectrum of a pectin that has not been treated with amylolytic enzymes [3, 7].

Conclusions. The analysis of the literature and our own research shows that the potato pulp is a source of dietary fiber and can be used in restaurant technologies for the enrichment of foodstuffs and to give them certain rheological properties.

The main technological properties of the obtained food powders were investigated. The high hydrophilicity and viscosity of the hydrated potato powders, as well as the biological value, make it possible to recommend them for food.

\section{REFERENCES}

1. Dmitrievich, L., Stepanova, T., (2012) Characterization of potato fiber and its use in different types of food systems. Bulletin of Sumy National Agrarian University. Series «Livestock», issue 10 (20), 2012. P. 139-142. 
2. Grishchenko, A., Yakimchuk, I., Shevchuk, U. (2009) Use of potato dietary fiber in baking. Materials of reports of 78th sciences conf. of young scientists, graduate students and students «Scientific achievements of youth - the solution of problems of nutrition of mankind in the XXI century, Ukraine, Kyiv.

3. Hrabovska, O., Pastukh, H., Lysyi, O., Miroshnyk, V., Shtangeeva, N. (2018). Use of enzyme preparations for pectin extraction from potato pulp, Ukrainian food journal. Volume 7(2). P. 215-234/

4. Hrabovska, O. V., Kovalevska, E. I., Maksimov, I. M., Similarity, O. V., (2017) Physical and Colloidal Chemistry. K. : NUCHT. (2017).

5. Kaack, K., Pedersen, L., Nygaard, H., Meyer, A. (2006) New potato fibre for improvement of texture and colour of wheat bread. European Food Research and Technology. № 224(2), P. 199-207.

6. Leshchenko, K. V. (2016) Perspective directions of improvement of micronutrient composition of flour confectionery. Modern problems and ways of their solution in science, transport, production and education. SWorld, June 7-14, (2016).

7. Mariusz, L., Wojciech, B., Grazyna, L. (2012). Enzymatic hydrolysis of potato pulp. Acta Scientarum Pololonorum. Techno. Aliment. 11(1) 2012, P. 53-59.

8. Oshchypok, M. I. (2015) The use of new food additives from vegetable raw materials in the food industry. Bulletin of the Lviv Commercial Academy. № 15, 2015. P. 77-81.

9. Rheological Characterization of Fiber Suspensions Prepared from Vegetable Pulp and Dried Fibers. A Comparative Study. Annual Transactions of the Nordic Rheology Society. (2005, July 12). Retrieved April 12, 2020, from http://citeseerx. ist. psu. edu/viewdoc/download?doi=10.1.1.662. 412\&rep=rep1\&type=pdf 